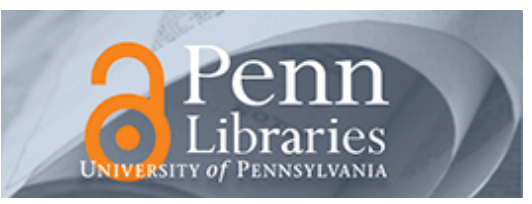

University of Pennsylvania

ScholarlyCommons

March 2001

\title{
Better Health While You Wait: A Controlled Trial of a Computer- Based Intervention for Screening and Health Promotion in the Emergency Department
}

\author{
Karin V. Rhodes \\ Diane S. Lauderdale \\ University of Chicago \\ Carol B. Stocking \\ University of Chicago \\ David S. Howes \\ University of Chicago \\ Michael F. Roizen \\ University of Chicago
}

University of Pennsylvania, kvr@sp2.upenn.edu

Sellowext thisaand fadditionahworksathor:https://repository.upenn.edu/spp_papers

\section{Recommended Citation}

Rhodes, K. V., Lauderdale, D. S., Stocking, C. B., Howes, D. S., Roizen, M. F., \& Levinson, W. (2001). Better Health While You Wait: A Controlled Trial of a Computer-Based Intervention for Screening and Health Promotion in the Emergency Department. Retrieved from https://repository.upenn.edu/spp_papers/103

Postprint version. Published in Annals of Emergency Medicine, Volume 37 Issue 3, March 2001, pages $284-291$. Publisher URL: http://dx.doi.org/10.1067/mem.2001.110818

NOTE: At the time of publication the author, Karin V. Rhodes, was affiliated with the University of Chicago. Currently, she is a faculty member with the School of Social Policy and Practice at the University of Pennsylvania.

This paper is posted at ScholarlyCommons. https://repository.upenn.edu/spp_papers/103

For more information, please contact repository@pobox.upenn.edu. 


\title{
Better Health While You Wait: A Controlled Trial of a Computer-Based Intervention for Screening and Health Promotion in the Emergency Department
}

\begin{abstract}
Study objective: We evaluate a computer-based intervention for screening and health promotion in the emergency department and determine its effect on patient recall of health advice.

Methods: This controlled clinical trial, with alternating assignment of patients to a computer intervention (prevention group) or usual care, was conducted in a university hospital ED. The study group consisted of 542 adult patients with nonurgent conditions. The study intervention was a self-administered computer survey generating individualized health information. Outcome measures were (1) patient willingness to take a computerized health risk assessment, (2) disclosure of behavioral risk factors, (3) requests for health information, and (4) remembered health advice.
\end{abstract}

Results: Eighty-nine percent (470/542) of eligible patients participated. Ninety percent were black. Eightyfive percent $(210 / 248)$ of patients in the prevention group disclosed 1 or more major behavioral risk factors including current smoking $(79 / 248 ; 32 \%)$, untreated hypertension $(28 / 248 ; 13 \%)$, problem drinking $(46 / 248 ; 19 \%)$, use of street drugs $(33 / 248 ; 13 \%)$, major depression $(87 / 248 ; 35 \%)$, unsafe sexual behavior (84/248; 33\%), and several other injury-prone behaviors. Ninety-five percent of patients in the prevention group requested health information. On follow-up at 1 week, $62 \%(133 / 216)$ of the prevention group patients compared with $27 \%(48 / 180)$ of the control subjects remembered receiving advice on what they could do to improve their health (relative risk $2.3,95 \%$ confidence interval 1.77 to 3.01 ).

Conclusion: Using a self-administered computer-based health risk assessment, the majority of patients in our urban ED disclosed important health risks and requested information. They were more likely than a control group to remember receiving advice on what they could do to improve their health. Computer methodology may enable physicians to use patient waiting time for health promotion and to target at-risk patients for specific interventions.

\section{Comments}

Postprint version. Published in Annals of Emergency Medicine, Volume 37 Issue 3, March 2001, pages 284-291.

Publisher URL: http://dx.doi.org/10.1067/mem.2001.110818

NOTE: At the time of publication the author, Karin V. Rhodes, was affiliated with the University of Chicago. Currently, she is a faculty member with the School of Social Policy and Practice at the University of Pennsylvania.

\section{Author(s)}

Karin V. Rhodes, Diane S. Lauderdale, Carol B. Stocking, David S. Howes, Michael F. Roizen, and Wendy Levinson 


\section{Better Health While You Wait: A Controlled Trial of a Computer-Based Intervention for Screening and Health Promotion in the Emergency Department}

From the Robert Wood Johnson Clinical Scholars Program*; Health Studies Department ${ }^{\ddagger}$; McLean Center for Medical Ethics ${ }^{\S}$; Sections of Emergency Medicine" and General Internal Medicine, ${ }^{\text {II Department of }}$ Medicine; and the Department of Anesthesia and Critical Care, University of Chicago, Chicago, IL.

Received for publication February 17, 2000. Revision received May 19, 2000. Accepted for publication June 27, 2000.

Supported by a grant from The Chicago Community Trust (No. 6-35467), the Robert Wood Johnson Clinical Scholars Program, and the University of Chicago Section of Emergency Medicine, Department of Medicine. Technical and computer program development support was provided by The Clinical Practice Enhancement and Anesthesia Research Foundation at the University of Chicago. The University of Chicago and 2 other universities have jointly licensed their rights in HealthQuiz to a nonprofit foundation. If this process is made financially viable, physicians at the University of Chicago Department of Anesthesia and Critical Care may benefit by support of their research. HealthQuiz is currently available free on the Internet at www.healthquiz.com.

The primary investigator on the project, Karin Rhodes, MD, is an emergency physician currently supported by the Robert Wood Johnson Foundation as a first-year fellow in the Clinical Scholars Program at the University of Chicago.

Address for reprints: Karin Rhodes, MD, University of Chicago, Robert Wood Johnson Clinical Scholars Program, 5841 S Maryland Avenue, MC 2007, B234, Chicago, IL 60637;
Karin V. Rhodes, MD*

Diane S. Lauderdale, $\mathrm{PhD}^{\ddagger}$

Carol B. Stocking, PhD\$

David S. Howes, MD"

Michael F. Roizen, MD\#

Wendy Levinson, MD"

773-834-4094, fax 773-702-1295; E-mailkrhodes@medicine.bsd. uchicago.edu.
Study objective: We evaluate a computer-based intervention for screening and health promotion in the emergency department and determine its effect on patient recall of health advice.

Methods: This controlled clinical trial, with alternating assignment of patients to a computer intervention (prevention group) or usual care, was conducted in a university hospital ED. The study group consisted of 542 adult patients with nonurgent conditions. The study intervention was a self-administered computer survey generating individualized health information. Outcome measures were (1) patient willingness to take a computerized health risk assessment, (2) disclosure of behavioral risk factors, (3) requests for health information, and (4) remembered health advice.

Results: Eighty-nine percent (470/542) of eligible patients participated. Ninety percent were black. Eighty-five percent (210/248) of patients in the prevention group disclosed 1 or more major behavioral risk factors including current smoking (79/248; 32\%), untreated hypertension (28/248; $13 \%$ ), problem drinking (46/248; 19\%), use of street drugs (33/248; 13\%), major depression (87/248; 35\%), unsafe sexual behavior (84/248; $33 \%$ ), and several other injury-prone behaviors. Ninety-five percent of patients in the prevention group requested health information. On follow-up at 1 week, 62\% (133/216) of the prevention group patients compared with $27 \%(48 / 180)$ of the control subjects remembered receiving advice on what they could do to improve their health (relative risk 2.3, 95\% confidence interval 1.77 to 3.01 ).

Conclusion: Using a self-administered computer-based health risk assessment, the majority of patients in our urban ED disclosed important health risks and requested information. They were more likely than a control group to remember receiving advice on what they could do to improve their health. Computer methodology may enable physicians to use patient waiting time for health promotion and to target at-risk patients for specific interventions. 
[Rhodes KV, Lauderdale DS, Stocking CB, Howes DS, Roizen MF, Levinson W. Better health while you wait: a controlled trial of a computer-based intervention for screening and health promotion in the emergency department. Ann Emerg Med. March

2001;37:284-291.]

\section{INTRODUCTION}

Two common problems in the emergency department are long waiting times and a failure to identify sensitive personal and public health risks. These stem from constraints on provider time. Could patient waiting time, commonly perceived as time wasted, be used as an opportunity for screening and health promotion? We hypothesized that we might be able to address these issues with the use of a selfadministered computer-based program. A review of the literature indicates that patients find computer-based health risk appraisal acceptable and are more likely to answer sensitive questions truthfully on a computer. ${ }^{1-5}$ However, there is limited experience with integrating interactive computer systems into clinical practice. ${ }^{6}$ We developed such a system, Prevent HealthQuiz, and evaluated its utility for nonurgent patients waiting for care in an urban ED.

The ED may constitute an advantageous venue for reaching out to people with serious health risks. There are approximately 100 million ED patient visits per year in the United States. Many ED patients are without a regular source of care.$^{7-9}$ Beyond the need for linkage to primary care and community-based resources, there is evidence that preventive services may be acceptable to ED patients ${ }^{10,11}$ and cost-effective, particularly for vulnerable populations. ${ }^{12-14}$ Most ED patients have acute health care problems but are not critically ill. In the ED setting, these patients are assigned to nonurgent triage categories and often spend a significant amount of time waiting to be seen by the physician. Is this waiting time a potential "teachable moment"?

We wanted to determine whether ED patients were interested in health risk assessment and health promotion. Further, we were interested in its effect on patient recall of health advice. Finally, we sought to assess the practical utility of using patient waiting time for screening and health education in a manner that would not interfere with patient flow in a busy inner-city ED.

\section{MATERIALS AND METHODS}

We conducted a controlled clinical trial of a computerbased health risk assessment in an inner-city university teaching hospital ED with approximately 38,000 adult visits per year, $40 \%$ of which are classified as nonurgent. Health care is provided by emergency medicine and internal medicine residents who are supervised by emergency medicine faculty members. Our study focused solely on patients assigned to nonurgent triage categories. We used a quasi-randomized design based on alternating assignment of patients to the intervention (prevention) and usual care (control) groups.

With previously validated questions that had been both clinically and computer tested, ${ }^{15-18}$ we developed a computer-based assessment of health risks, targeting those that could be modified by behavioral or life-style changes. A pilot phase included cognitive interviewing ${ }^{19}$ with a convenience sample of 141 nonurgent ED patients and patient relatives of varying ages and educational backgrounds to ensure content and construct validity. The final form of the prevention HealthQuiz has 145 questions at a fifth-grade reading level covering 8 categories of health-related behaviors and personal health. A complete interview contains answers to approximately 80 to 100 of these questions, because of skips based on age, sex, and previous answers. Twenty-three questions ask about demographic variables or access to care and 30 others either introduce topics or ask whether the patient would like information about a topic. Average response times are 15 minutes for men and 18 minutes for women, who are asked additional cancer and contraceptive-related questions.

After completing the questionnaire, patients receive individualized computer-generated health recommendations and any additional information requested during the questionnaire. For the treating physician, the computer program generates a 1-page summary with the patient's demographic information, major health risks, and referral information.

From July 1998 through January 1999, 4 part-time research assistants recruited eligible patients from the ED waiting room after triage and registration. Study periods were between $10 \mathrm{Am}$ and $10 \mathrm{PM}$ on a convenience selection of weekdays and weekends. Eligible patients were Englishspeaking adults whose condition at triage was nonurgent who had access to a telephone and agreed to a follow-up telephone interview. Patients were excluded if they were in pain, blind, overtly psychotic, or unable to read. Not all eligible patients were enrolled because of limited computer availability. To avoid selection bias, when the computer was available the patient to be recruited was the one who most recently arrived and assigned as nonurgent at triage. After a successful recruitment to the prevention group, the next most recently arrived patient was assigned to the 
control group. Patients gave verbal consent to a scripted introduction that specified that the computer questionnaire asked questions about their health and lifestyle and told them this information would be shared with the treating physician during the current visit. Prevention patients used a touch screen computer and a Web-based questionnaire. This took place in a private setting attached to the ED waiting room. Friends and family were not allowed to be present. We interrupted the questionnaire if the patient was called to the treatment room. All patients were analyzed on the basis of the group in which they were enrolled, regardless of whether they completed the questionnaire. This study complied with the human subjects' protection requirements and was approved by the university's institutional review board.

Study data were collected and entered into an Excel database (Microsoft, Redmond, WA). The research assistants kept a record of all patients who were approached and any reasons for refusal. They noted if patients started but did not complete the computer questionnaire, any need for computer assistance, and recorded all patient comments. The research nurse monitored data collection and coding quality and was available to the research assistants for questions about study procedures. All patients received a follow-up telephone call approximately 1 week after their visit. The research assistant making the telephone call was blinded as to the patient's group assignment. If the patient was not contacted on the first attempt, repeat follow-up was attempted during each subsequent study session up to a maximum of 10 attempts. If necessary, messages were left and there was a number for the patient to call back during working hours.

To evaluate patient interest and risks, we assessed behavioral risk factors and numbers of requests for health information. This information was collected from the prevention group interview database. Information about the patients' reactions to the ED visit was collected during blinded follow-up telephone calls from both groups. The telephone interview asked about visit satisfaction, followup with appointments, suggestions for improvement of ED care, and whether patients remembered being given any advice regarding what they could do to improve their health.

We determined proportions of eligible patients willing to take a computer-based health risk assessment and the proportions assigned to the prevention group who completed the questionnaire. From the data entered by patients taking the computer questionnaire, we looked at the numbers and percentages of behavioral risks and requested health information. We also compared the proportions of each group remembering being given advice on what they could do to improve their health. $\chi^{2}$ Tests were used to compare the groups regarding remembered advice. The magnitudes of effect were calculated as relative risks, with 95\% confidence intervals. All data were analyzed by using Stata6 statistical software (release 6.0, 1999; StataCorp, College Station, TX).

\section{RESULTS}

During a 6-month period, the research assistants approached 570 nonurgent patients. Twenty-eight were ineligible because of pain $(n=21)$ or had no access to a telephone $(n=7)$. Four hundred eighty-three $(89 \%)$ of eligible patients agreed to participate, and 470 of them were enrolled into 1 of the 2 study arms. The remaining 13 patients were called for treatment before being assigned. Two hundred forty-eight patients were assigned to the prevention group and 222 patients were assigned to the control group. The difference in numbers was an artifact of the alternating assignment because each study period

\section{Table 1.}

Comparison of demographic variables and reasons for visit for control and prevention group patients.

\begin{tabular}{|c|c|c|}
\hline & \multicolumn{2}{|c|}{ Study Patients (Total=470) } \\
\hline & $\begin{array}{c}\text { Control Group } \\
(\mathrm{N}=222) \\
\text { No. }(\%)\end{array}$ & $\begin{array}{c}\text { Prevention Group } \\
(\mathrm{N}=248) \\
\text { No. }(\%)\end{array}$ \\
\hline \multicolumn{3}{|l|}{ Disposition } \\
\hline Discharged home & $157(71)$ & $191(77)$ \\
\hline LWBS & $27(12)$ & $20(8)$ \\
\hline Admitted & $11(5)$ & $8(3)$ \\
\hline Disposition not documented & 27 (12) & $29(12)$ \\
\hline \multicolumn{3}{|l|}{ Sex } \\
\hline Men & 70 (32) & 78 (32) \\
\hline Women & $152(68)$ & $170(68)$ \\
\hline Average age (y) & 42 & 36 \\
\hline \multicolumn{3}{|l|}{ Race $^{\dagger}$} \\
\hline White & $21(10)$ & $16(7)$ \\
\hline Black & 187 (84) & 226 (91) \\
\hline Other & $1(1)$ & $6(2)$ \\
\hline Missing data & $13(6)$ & \\
\hline \multicolumn{3}{|l|}{ Reason for visit } \\
\hline Medical & $125(56)$ & $124(50)$ \\
\hline Injury & $46(21)$ & $68(27)$ \\
\hline Gynecologic/urinary & $32(14)$ & $49(20)$ \\
\hline Other reasons/missing data & $19(9)$ & $7(3)$ \\
\hline
\end{tabular}


began with a prevention group assignment, thus approximately half of the sessions resulted in 1 more prevention than control patient. A total of 232 patients (94\%) of those assigned to the prevention group completed the questionnaire before being called to the treatment room (Figure).

Our study population reflected the composition of our nonurgent ED patients who are urban and predominantly black women. The control patients were similar to the prevention patients (Table 1). There were no significant differences in race or sex. The control group was on average 6 years older and $6 \%$ more likely to have a medical than an injury-related reason for visit. Both groups had the same proportion of gynecologic-urinary complaints. During study periods, the rate of all ED patients leaving without being seen (LWBS) by a physician ranged from $3 \%$ to $20 \%$ with an average of $8 \%$ for all levels of severity; this is much higher for nonurgent patients who were the subjects of this study. Rates of LWBS were $12 \%$ for control and $8 \%$ for prevention patients. Of note, $4 \%$ of our non- urgent study patients were admitted. Additional demographic characteristics were collected as part of the computer questionnaire for the prevention group only (Table 2). An evaluation of access to care variables in this group found that $29 \%$ were privately insured, $54 \%$ were covered by Medicaid or Medicare, and $12 \%$ had no health insurance; $27 \%$ had no usual source of care outside the ED.

Eighty-five percent (210/248) of patients in the ED prevention group disclosed 1 or major behavioral risk factors including current smoking (32\%), untreated hypertension (13\%), problem drinking (19\%), use of street drugs (13\%), major depression (35\%), and unsafe sexual behavior (32\%) (Table 3). Other injury-prone behaviors included driving within 4 hours of having 2 or more drinks (11\%), inconsistent use of seat belts (40\%), not having a smoke detector that has been checked in the past year (17\%), a history of witnessing knife or gun violence ( $31 \%$ of men, $18 \%$ of women), and having a hand-

\section{Figure.}

Study flow diagram.

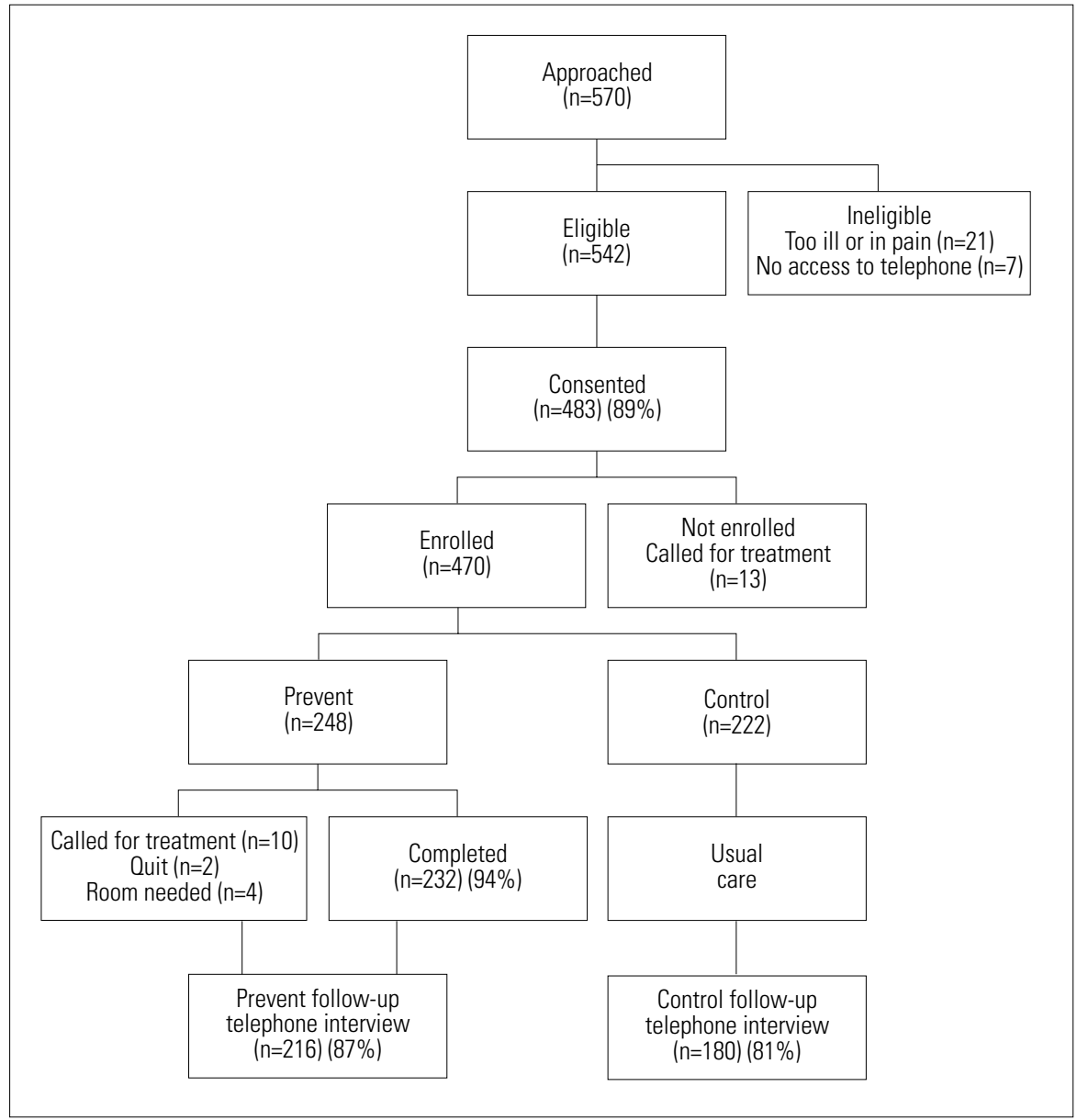


gun at home or in the car ( $21 \%$ of men, $6 \%$ of women). Of importance, the large majority (95\%) of patients who completed the computer questionnaire elected to receive additional information about specific health topics (Table 4).

We were able to contact 396 of the 470 study patients for a follow-up telephone interview, including 180 (81\%) of 222 control patients and 216 (87\%) of 248 in the prevention group. In the follow-up interviews, 62\% (133/216) of prevention group patients contacted, compared with $27 \%$ (48/180) of the control patients, reported having received advice on what they could do to improve their health (relative risk 2.3, 95\% confidence interval 1.77 to 3.01) Although patient comments about the prevention questionnaire were overwhelmingly positive, there was no difference in overall visit satisfaction (mean rating 1.7 on a 1-to-3 scale, with 1 being "very satisfied") or having

\footnotetext{
Table 2.

Additional demographic and access to care variables for patients who took computer questionnaire.
}

\begin{tabular}{lc} 
Variable & $\%$ \\
\hline & \\
Education & \\
<High school & 21 \\
Trade school & 7 \\
High school diploma & 38 \\
College degree & 27 \\
Graduate school & 5 \\
Doctorate/professional school & 2 \\
Insurance & \\
Medicaid & 37 \\
Medicare & 17 \\
Private & 29 \\
Self-pay & 12 \\
Student health/worker compensation & 5 \\
Marital status & \\
Married & 19 \\
Single & 60 \\
Divorced/separated & 17 \\
Widowed & 4 \\
Usual source of care & \\
ED & 17 \\
None & 10 \\
Health maintenance organization & 10 \\
Hospital clinic & 31 \\
Neighborhood clinic & 18 \\
Primary physician office & 14 \\
Duration of symptoms prompting ED visit & \\
$<1$ d & 21 \\
$<1$ wk but $>1$ d & 44 \\
$<1$ mo but $>1$ wk & 22 \\
$<1$ y but $>1$ mo & 7 \\
$>1$ y & 6 \\
*0ther demographic data for prevention group only (N=248) (data from computer questionnaire). \\
\end{tabular}

called a referral number (mean, 50\%) 1 week after the ED visit.

\section{DISCUSSION}

We found it feasible to use computer survey technology for risk factor screening and health promotion in the acute care setting. ED patients were very accepting of this technology and interested in using their waiting time as an opportunity to receive health information. Of importance, patients receiving the computer intervention were more likely than the control group to remember being given health advice 1 week after the ED visit.

Table 3.

Behavioral risk factors disclosed on computer questionnaire.

\begin{tabular}{|c|c|}
\hline Topics and Definitions of Risk Factors & $\begin{array}{c}\text { Patients } \\
\text { Disclosing } \\
\text { Risks on the } \\
\text { Computer } \\
\text { Questionnaire* } \\
\text { (N=248) } \\
\text { No. (\%) }\end{array}$ \\
\hline Overall disclosure of at least 1 behavioral risk factor ${ }^{*}$ & $210(85)$ \\
\hline Use of street drugs ${ }^{\dagger}$ & $33(13)$ \\
\hline Use of street drugs in last 4 weeks & $29(12)$ \\
\hline History of intravenous drug use & $7(3)$ \\
\hline Problem drinking ${ }^{\dagger}$ & $46(19)$ \\
\hline Sometimes $>4$ drinks/d and drinking at least 3 times/wk (or) & $36(15)$ \\
\hline At least 1 positive response to CAGE (test for alcoholism) & $40(16)$ \\
\hline Cardiovascular behavioral risks $^{\dagger}$ & $92(37)$ \\
\hline Smokes cigarettes & $79(32)$ \\
\hline History of hypertension and not taking blood pressure medication & $28(13)$ \\
\hline Major depression ${ }^{\dagger}$ & $87(35)$ \\
\hline Depressed $>2$ wk in row in past 12 months & $79(33)$ \\
\hline Suicidal ideation in last $12 \mathrm{mo}$ & $33(13)$ \\
\hline High-risk sexual behavior ${ }^{\dagger}$ & $84(33)$ \\
\hline Nonuse of condoms and at least 1 of the following: & $137(55)$ \\
\hline History of sexually transmitted disease in past 5 y & $58(23)$ \\
\hline Partner with sexually transmitted disease in past year & $31(13)$ \\
\hline$>1$ sexual partner in past year & $47(19)$ \\
\hline History of or sexual exposure to prostitution & $11(5)$ \\
\hline Other injury-prone behaviors ${ }^{\dagger}$ & $155(62)$ \\
\hline Driving within $4 \mathrm{~h}$ of drinking $\geq 2$ alcoholic drinks & $26(11)$ \\
\hline Does not always use seat belt & $100(40)$ \\
\hline Does not have/has not checked smoke detector in past year & $42(17)$ \\
\hline Has handgun in home or car & $28(11)$ \\
\hline History of witnessing or participating in knife/gun violence & $54(22)$ \\
\hline \multicolumn{2}{|c|}{$\begin{array}{l}\text { *A disclosure was defined as a response of "Yes" to the question but also included "Not sure" } \\
\text { responses only in the areas of patient disclosure of suicidal ideation and "No" to questions } \\
\text { about taking medication for hypertension or having a smoke detector that has been checked by } \\
\text { someone in the past year. } \\
\text { 'Summaries. }\end{array}$} \\
\hline
\end{tabular}


The US Preventive Services Task Force and Centers for Disease Control and Prevention have recommended that all physicians take advantage of acute care visits to provide screening and counseling for selected health risk behaviors. ${ }^{20,21}$ Meeting this standard is difficult given current market constraints that require physicians to give more service in less time with less staff support. Increased emphasis on information technology may help physicians to manage the competing priorities of medical care. A recent systematic review of the major studies of computer-based clinical decision support systems for medical providers found them to be effective in enhancing preventive care. ${ }^{22}$ A 1999 review of computer-based interactive health systems found them to be efficacious for delivering behavioral counseling, both as stand-alone interventions or as adjuncts to physician counseling. ${ }^{23}$ Another review of survey methodology found computer-based technology improved the accuracy of data collection for survey

\section{Table 4.}

Requests for specific health information for self or others. *

\begin{tabular}{|c|c|}
\hline $\begin{array}{l}\text { Topics on Which } \\
\text { ED Patients Requested } \\
\text { Health Information }\end{array}$ & $\begin{array}{l}\text { Respondents } \\
\text { Answering "Yes" } \\
\text { When Asked If } \\
\text { They Would Like } \\
\text { Information' } \\
\text { No. }(\%)\end{array}$ \\
\hline \multicolumn{2}{|l|}{ How to: } \\
\hline Exercise for health & $194 / 243(80)$ \\
\hline Prevent or control high cholesterol & $160 / 243(66)$ \\
\hline Control high blood pressure and prevent stroke & $171 / 243(70)$ \\
\hline Lower chances of having a heart attack & $192 / 243(79)$ \\
\hline $\begin{array}{l}\text { Learn cardiopulmonary resuscitation } \\
\text { (asked if no previous course) }\end{array}$ & 135/153 (88) \\
\hline Get help for a drug problem* & $95 / 232(41)$ \\
\hline Get help for depression ${ }^{*}$ & $122 / 242(50)$ \\
\hline $\begin{array}{l}\text { Avoid unwanted pregnancies (asked of women }<50 \text { y } \\
\text { and no surgical sterilization) }\end{array}$ & 25/84 (30) \\
\hline Lower uterine and cervical cancer risks & $119 / 153(78)$ \\
\hline Detect breast cancer at early stage & $124 / 165(75)$ \\
\hline Quit smoking ${ }^{*}$ & $121 / 240(50)$ \\
\hline Get help for a drinking problem ${ }^{*}$ & $54 / 240(22)$ \\
\hline Prevent sexually transmitted disease ${ }^{*}$ & $102 / 232(44)$ \\
\hline Prevent or be tested for HIV/AIDS* & $105 / 232(45)$ \\
\hline $\begin{array}{l}\text { Overall no. of patients requesting health information } \\
\text { on } 1 \text { or more topics }\end{array}$ & $235 / 248(95)$ \\
\hline \multicolumn{2}{|c|}{$\begin{array}{l}{ }^{*} \text { For these topics, patients were asked whether they would like information for themselves or } \\
\text { for someone else. The format of the question was designed to permit nondisclosure of persona } \\
\text { risks while asking for information about the topic. } \\
\text { †The percentage of requests on each individual topic is calculated only for patients who were } \\
\text { asked the question. Because of branches and skips and partial completion of some question- } \\
\text { naires, the denominator for people answering a question varies. }\end{array}$} \\
\hline
\end{tabular}

research. ${ }^{24}$ However, to our knowledge there are no reports evaluating the effectiveness of combining computer-based screening with interactive patient health education in an acute care setting. The fact that $95 \%$ of nonurgent ED patients taking a computer questionnaire requested health information lends support for the use of computer-based technology for screening and health promotion as an adjunct to usual acute care.

The printed health information generated by the computer program was well received by patients. It gave them something to read while in the department and to take home for review. In fact, requests for health information frequently exceeded the number of patients disclosing personal risks for that topic. We believe these increased requests represented a desire to pass on health information to friends or family members. As evidence for this, only $32 \%$ of patients said they were current smokers, but an additional $20 \%$ lived with a smoker, and $50 \%$ of the patients said they would like to get information for themselves or someone else on how to quit smoking. This would make a strong case for the extension of the potential health benefits beyond the individual patient receiving care. On the other hand, it may also represent undisclosed health risks in our patients.

Other investigations set in the ED environment have revealed significant numbers of patients with serious personal and public health risks. ${ }^{25-28}$ Some of these behaviors have been found to be strongly related cofactors and independent predictors of poor health and adverse social outcomes. ${ }^{29}$ For example, a single alcohol-related ED visit was found to be predictive of future arrest for alcoholimpaired driving, future ED visits for suicidal behavior or domestic violence, and increased 5-year mortality. ${ }^{30}$ Although screening and intervention for health risk factors have not been standard practice in the ED setting, ${ }^{31}$ emergency physicians have recently started to quantify these risks and explore potential interventions with some positive results. ${ }^{32,33}$

Compared with a control group, patients in our study who took the computer-based questionnaire had increased recall of having received advice about what they could do to improve their health. What factors led to this increase? One possibility is that the printed computergenerated health recommendations by themselves had an impact or perhaps patients were remembering physician reinforcement of those health recommendations, although we rarely found documentation of such counseling. Another hypothesis is that taking the health questionnaire had the effect of activating the patient in the waiting room and this resulted in enhanced physician/patient commu- 
nication. This would be analogous to work by Kaplan et al ${ }^{34}$ and Greenfield et al, ${ }^{35}$ who demonstrated that diabetic patients prepared in the waiting room before a visit with their physician had improved blood glucose control. Our study design did not allow for direct exploration of mechanisms that contribute to motivating behavioral change.

There has been speculation as to whether the ED visit is really an opportunity for prevention, or just a chaotic and confusing time for the patient and family. Recent ED evidence suggests that preventive interventions directly related to the reason for visit can be effective. Parents trained about suicide risks during an ED visit for an adolescent behavior problem were 4 times more likely to take steps to limit their child's access to guns and prescription drugs than parents without the training. ${ }^{36}$ Our data suggest that the ED setting is conducive to providing a teachable moment for preventive health messages, regardless of whether those messages are related to the reason for visit.

The generalizability of our results may be diminished in that our study took place in a single urban university hospital ED with a predominantly black patient population who were experiencing significant waiting times before being seen by a physician. In addition, when we alternately assigned patients by order of arrival to either the control or the prevention groups, we were randomizing by queue as opposed to a true random selection technique. Although we did not believe this would lead to a systematic selection bias, this process probably resulted in a younger population in the prevention group than in the control group. Regarding the age difference, we hypothesize that older patients were called back for treatment sooner and were therefore less likely to be waiting when the computer resources were available. Therefore, our assumption that the control group had approximately the same proportion of behavioral health risks as the intervention group may not be accurate. Finally, although we report an increase in remembered health advice, we did not, and could not, examine actual behavioral change. Although the intuition is that remembering health advice would be an important first step, this study was not designed to evaluate whether advice was related to behavioral change.

In summary, we explored the use of information technology as a method of using patient waiting time for screening and health promotion. In our study, computer health risk assessment was acceptable to patients and resulted in the majority of patients disclosing important behavioral health risks and requesting health information. Compared with a control group, the intervention group was more likely to remember receiving health advice. Computer-based interactive technology may enable EDs and other clinical settings with significant amounts of patient waiting time to use that time for health promotion and to help identify patients who might benefit from more specific interventions.

We acknowledge the contributions of James Walter, MD, Linda Druelinger, MD, Jon Olsen, MD, Robert Mulliken, MD, Jack Iwashyna, Richard Kim, Lance Becker, MD, Terry VandenHoek, MD, Annette Miller, RN, Sue French, RN, David Mingay, PhD, and Dexter Voisin, PhD. In addition, John Bailar, MD, Marshall Chin, MD, and Nicholas Christakis, MD, PhD, provided valuable editorial advice.

\section{REFERENCES}

1. Tourangeau R, Smith TW. Asking sensitive questions: the impact of data collection mode, question format, and question context. Public Opinion Quarterly. 1996;60:274-304.

2. Ellis LBM, Joo HY, Gross CR. Use of computer-based health risk appraisal by older adults. J Fam Pract. 1991;33:390-394.

3. Roizen MF, Coalson D, Hayward RSA, et al. Can patients use an automated questionnaire to define their current health status? Med Care. 1992;30:MS74-MS84.

4. Locke SE, Kowaloff HB, Hoff RG, et al. Computer-based interview for screening blood donors for risk of HIV transmission. JAMA. 1992;268:1301-1305.

5. Robinson R, West R. A comparison of computer and questionnaire methods of history-taking in a genito-urinary clinic. Psychol Health. 1992;6:77-84.

6. Gustafson DH, Hawkins R, Boberg E, et al. Impact of a computer-based health information/support system. Am J Prev Med. 1999;16:1-9.

7. Baker DW, Stevens CD, Brook RH. Regular source of ambulatory care and medical care utilization by patients presenting to a public hospital emergency department. JAMA. 1994;271:1909-1912.

8. Young GP, Wagner MB, Kellermann AL, et al. Ambulatory visits to hospital emergency departments, patterns and reasons for use. JAMA. 1996;276:460-465.

9. O'Brian $\mathrm{GM}$, Stein $\mathrm{MD}$, Zierler $\mathrm{S}$, et al. Use of the $\mathrm{ED}$ as a regular source of care: associated factors beyond lack of health insurance. Ann Emerg Med. 1997;30:286-29.

10. Rodrigues RM, Kreider WJ, Baraff LJ. Need and desire for preventive care measures in emergency department patients. Ann Emerg Med. 1995;26:615-620.

11. Strange KC, Flocke SA, Goodwin MA. Opportunistic preventive services delivery: are there time limitations and patient satisfaction barriers? J Fam Pract. 1998;47:202-208.

12. Stack SJ, Martin DR, Plouffe JF. An emergency department-based pneumococcal vaccination program could save money and lives. Ann Emerg Med. 1999;33:299-303.

13. Ernst AA, Romolo R, Nick T. Emergency department screening for syphilis in pregnant women without prenatal care. Ann Emerg Med 1993;22:781-785.

14. Mandelblatt JS, Freeman H, Winczewski D, et al. The costs and effects of cervical and breast cancer screening in a public hospital emergency room. Am J Public Health. 1997;87:11821189.

15. Lutner RE, Roizen MF, Stocking CB, et al. The automated interview versus the personal interview: do patient responses to preoperative health questions differ? Anesthesiology. 1991;75:394-400.

16. Hayward RSA, Smittner JP, Meyer $\mathrm{P}$, et al. Computer versus interview administered preventive care questionnaire: does survey medium affect patient response reliability? In: Report from the Clinical Practice Enhancement Project, Prevention Practice Project-Reliability. Hamilton, Ontario: McMaster University; 1996.

17. Warshaw C, Ganley AL, Salber PR. Improving the Health Care Response to Domestic Violence: a Resource Manual for Health Care Providers. 2nd ed. San Francisco, CA: The Family Violence Prevention Fund; 1996.

18. Feldhaus KM, Koziol-McLain J, Amsbury HL, et al. Accuracy of 3 brief screening questions for detecting partner violence in the emergency department. JAMA. 1997;277:1357-61.

19. Jobe JB, Mingay DJ. Cognitive research improves questionnaires. Am J Public Health 1989;79:1053-1055 
20. US Preventive Services Task Force. Guide to Clinical Preventive Services. 2nd ed. Baltimore, MD: Williams \& Wilkins; 1996.

21. Putting prevention into practice. Available at: http://www.ahcpr.gov/ppip.htm.

22. Hunt DL, Haynes RB, Hanna SE, et al. Effects of computer-based clinical decision support systems on physician performance and patient outcomes: a systematic review. JAMA. 1998;280:1339-1346.

23. Noell J, Glascoe RE. Interactive technology applications for behavioral counseling: issues and opportunities for the health care setting. Am J Prev Med. 1999;17:269-274.

24. MacMillian HL. Computer survey technology: a window on sensitive issues. Can Medical Assoc J. 1999;161:1142.

25. Rodewald LE, Szilagyi PG, Humiston SG, et al. Is an emergency department visit a marker for undervaccination and missed opportunities among children who have access to primary care? Pediatrics. 1993;91:605-611.

26. Abbott J, Johnson R, Koziol-McLain J, et al. Domestic violence against women: incidence and prevalence in an emergency department population. JAMA. 1995;273:1763-67.

27. Hogness CG, Engelstad LP, Linck LM, et al. Cervical cancer screening in an urban emergency department. Ann Emerg Med. 1992;21:933-939.

28. Ernst AA, Romolo R, Nick T. Emergency department screening for syphilis in pregnant women without prenatal care. Ann Emerg Med. 1993;22:781-785.

29. El-Bassel N, Gilbert L, Krishnan S, et al. Partner violence and sexual HIV-risk behaviors among women in an inner-city emergency department. Violence Vict. 1998;13:377-393.

30. Davidson P, Koziol-McLain J, Harrison L, et al. Intoxicated ED patients: a 5-year follow-up of morbidity and mortality. Ann Emerg Med. 1997;?:593-597.

31. Lowenstein S, Weissberg M, Terry D. Alcohol intoxication, injuries, dangerous behaviors and the revolving emergency department door. J Trauma. 1990;30:1252-57.

32. Bernstein E, Bernstein J, Levenson S. Project ASSERT: an ED based intervention to increase access to primary care, preventative services, and the substance abuse treatment system. Ann Emerg Med. 1997;30:181-189.

33. Bernstein E, Bernstein J, eds. Case Studies in Emergency Medicine and the Health of the Public. Sudbury, MA: Jones \& Barlett Publishers; 1996.

34. Kaplan SH, Greenfield S, Ware JE. Assessing the effects of physician-patient interactions on the outcomes of chronic disease. Med Care. 1989;27:S110-S127.

35. Greenfield S, Kaplan SH, Ware JE, et al. Patient's participation in medical care: effects on blood sugar control and quality of life in diabetes. J Gen Intern Med. 1988:3:448-457.

36. Kruesi MJP, Grossman J, Pennington JM, et al. Suicide and violence prevention: parent education in the emergency department. J Am Acad Child Adolesc Psychiatry. 1999;38:250-255. 